\title{
The Representativeness of Online Time Use Surveys. Effects of Individual Time Use Patterns and Survey Design on the Timing of Survey Dropout
}

\author{
Petrus te Braak ${ }^{1}$, Joeri Minnen ${ }^{1}$, and Ignace Glorieux ${ }^{1}$
}

\begin{abstract}
Like other surveys, time use surveys are facing declining response rates. At the same time paper-and-pencil surveys are increasingly replaced by online surveys. Both the declining response rates and the shift to online research are expected to have an impact on the representativeness of survey data questioning whether they are still the most suitable instrument to obtain a reliable view on the organization of daily life. This contribution examines the representativeness of a self-administered online time use survey using Belgian data collected in 2013 and 2014. The design of the study was deliberately chosen to test the automated processes that replace interviewer support and its cost-efficiency. We use weighting coefficients, a life table and discrete-time survival analyses to better understand the timing and selectivity of dropout, with a focus on the effects of individual time use patterns and the survey design. The results show that there are three major hurdles that cause large groups of respondents to drop out. This dropout is selective, and this selectivity differs according to the dropout moment. The contribution aims to provide a better insight in dropout during the fieldwork and tries to contribute to the further improvement of survey methodology of online time use surveys.
\end{abstract}

Key words: Nonresponse; time use survey; survey design; online research.

\section{Introduction}

About 120 years ago, random sampling was proposed for population research (Bethlehem 2009). Before that time, elite consultations were often used for policy preparation. In particular socialist politicians perceived the survey sample as a democratic way to gauge the population for policy making (Savage and Burrows 2009). The aim of the random sample was to construct no less than a small society. Sample surveys were supposed to value everyone's opinion, regardless of one's socioeconomic status, and were therefore preferred over elitist policy making commissions.

Soon after the first practical applications of this approach, scholars started questioning nonresponse and the democratic nature of random sample surveys: with ever declining response rates (Curtin et al. 2000; Connelly et al. 2003; Cull et al. 2005; Johnson and Wislar 2012), that are disproportionally observed in groups of lower social background

\footnotetext{
${ }^{1}$ Vrije Universiteit Brussel, Department of Sociology, Research Group Tempus Omnia Revelat (TOR), Pleinlaan 2, 1050 Brussels, Belgium. Emails: ptebraak@vub.be, Joeri.Minnen@vub.be and Ignace.Glorieux@vub.be Acknowledgments: We would like to thank the five anonymous referees for their careful and constructive reviews, which led to substantial improvements of this manuscript.
} 
(Smith 2008; Porter and Whitcomb 2005), it is questionable whether sample surveys are still the democratic and representative method they once were supposed to be.

The same question applies to time use surveys. This approach has been historically developed to gain insight in the time use patterns for the purposes of planning of all sorts of organization of public life, such as working hours, traffic, household work, and sleeping time (Szalai 1966). This implies, of course, the inclusion of all social strata in society. Pääkkönen (1998) and Knulst and Van den Broek (1998), however, showed that time use surveys, too, are prone to selective nonresponse, which raises the question whether time use surveys are the right instrument to gain insight of the organization of public life. There may be an extra bias in such research, because a time use survey consists of several phases. Where "normal" survey research only consists of a questionnaire, a time use survey using a diary approach (of course this situation differs from other methodologies such as a telephone recall interview approach, used for the ATUS, see, for example Abraham et al. 2006) continues with a diary that needs to be kept over one or several days. The sequencing of these tasks, the atypical research method and the longer research period results in a higher participation burden (Pääkkönen 1998; Knulst and Van den Broek 1998). This leads to the question whether there may be two phases in which nonresponse takes place: (1) whether or not to accept the invite and complete the questionnaire; and (2) whether or not to complete the time diary after the questionnaire has been completed.

In addition to the differences between usual survey research and time use surveys, we have seen a second divide in methodology in recent years: the difference between paperand-pencil surveys and online surveys. There is an interest to replace the traditional paperand-pencil-(time use) survey by online surveys, in order to save costs, to speed up the fieldwork, and to avoid using interviewers who inevitably can cause bias. An emerging literature around nonresponse in online surveys shows that this method leads to extra bias due to its specific survey design (Couper et al. 2007; Smith 2008; Kwak and Radler 2002). The effects of this relatively new survey method on nonresponse, especially when used in a time use survey is, to our knowledge, still uncharted territory.

This article attempts to contribute to the debate on nonresponse in online time use surveys (OTUS) specifically. In 2013, an OTUS was conducted in Flanders (Belgium). In this contribution, we will elaborate on the timing of dropout during the fieldwork, and we will also discuss the selectivity of the dropout by (1) comparing the response during the questionnaire phase with other representative data from the same research population; and (2) by comparing the population of respondents of a successive survey with respondents of the base survey, to investigate the selectivity of dropout during the diary stage, as suggested by Porter and Whitcomb (2005) and Johnson and Wislar (2012).

The remainder of this article is structured as follows: firstly, we give an overview of existing literature on nonresponse in general and especially on nonresponse in time use surveys. Secondly, we describe the research design and data we use in order to shed light on the timing and selectivity of nonresponse in one of the first online time use surveys and formulate our hypotheses. Thirdly, we describe the results of the analyses. Lastly, we conclude by discussing the results in the light of the existing literature. 


\section{Literature Overview}

Nonresponse bias in surveys can be related to the following aspects: background variables, behavior related to, or interest in, the research topic, or the survey design. In this section, these aspects are dealt with interchangeably, because there are often interrelationships between the aspects that lead to nonresponse. Studies on nonresponse bias in online surveys suggest that those research methods show in general the same nonresponse patterns as those of traditional paper-and-pencil surveys (Couper et al. 2007), although some other response patterns compared to paper-and-pencil surveys were found as well (Kwak and Radler 2002; Couper et al. 2007; Sax et al. 2003). For this literature review, we therefore concentrate mainly on variables related to time and on nonresponse in online surveys specifically.

In existing literature on nonresponse in time use surveys, often the focus is solely on the ultimate representativeness of such a survey, without taking into account the different phases of such a study. As far as we know, there is no existing literature about the possible extra bias caused by the additional nonresponse stemming from the diary phase in a time use survey. This makes it virtually impossible to know whether such a research design leads to an additional dropout and selectivity compared to a conventional research design. However, an extra bias would not be entirely illogical. Some groups might still be willing to fill in a questionnaire, but as soon as they experience the workload of a diary, they still drop out. Reasons for this may include, among others, the complexity, the degree of repetitiveness, but also time constraints. Our first hypothesis is therefore that there are two different research phases in which nonresponse occurs: the first dropout occurs before finishing the questionnaire, the second when completing the diary (H1). We expect that the nature of this dropout is selective and that the selectivity (partly) differs between the phases (i.e., that we see certain groups dropout more often during the questionnaire phase and for other covariates during the diary phase). We will formulate specific hypotheses about the dropout during the different stages for the different covariates.

In existing nonresponse literature, analyses generally show that socioeconomic status (SES) is one of the major causes of nonresponse bias in sample surveys of the general population (Porter and Whitcomb 2005). Others formulate this more specifically in terms of educational attainment: a lower level of education is related to lower levels of participation (Curtin et al. 2000; Singer et al. 1999). In the past, the higher nonresponse of the lower social strata was seen as a result of illiteracy (Goyder et al. 2002; Wallace 1954). Nowadays, illiteracy is not a problem with the same dimension anymore. However, as Goyder et al. (2002) make clear, mail surveys tend to have a higher SES bias compared to telephone surveys, indicating that probably the written language of paper-and-pencil surveys can still form a problem for some groups of potential respondents. One can argue that the same holds for OTUS, leading to the hypothesis that the lower educated persons will have a lower response rate on the questionnaire of the OTUS than their higher educated counterparts (H2q, for questionnaire), because the online context does not change the use of language in such a survey. However, language is less of a problem when filling in the diaries, because the structure of the questions is far less complex than for a questionnaire and the questions during the diary are very repetitive (what do you do, when, with whom?). In addition, a selection effect will have already taken place during the pre- 
questionnaire, as a result of which low-literate people may have already dropped out. As a result, we do expect no additional dropout from the lower educated during the diary phase (H2d, for diary).

In addition to SES, gender is usually identified as a significant predictor of survey participation (Curtin et al. 2000; Singer et al. 2000; Porter and Whitcomb 2005; Cull et al. 2005). Usually, scholars find that women are more willing to participate than men. However, there are also examples where no gender bias was found (Etter and Perneger 1997). Smith (2008) suggests that the willingness to participate is likely to be the result of how men and women make decisions. Female characteristics like empathy and emotional closeness are related, from this point of view, to survey participation. The overrepresentation of women is confirmed in some online surveys (Smith 2008; Sax et al. 2003). In another study, however, where Kwak and Radler (2002) compared mail and web-based surveys, they found that women were overrepresented in the mail survey and, surprisingly, underrepresented in the web-based survey (see also Dillman et al. 2009). The researchers explain this gender difference as men being more intensively involved with new technologies. Although this may have been the case in 2002, this hardly seems to be valid anymore. For these reasons, and in line with the discussed literature, we hypothesize that women participate more in online time use surveys than men and that thus their dropout is lower during the questionnaire phase (H3q), as well as during the diary phase ( $\mathrm{H} 3 \mathrm{~d})$.

The relation between age and survey participation is, based on existing literature, rather unclear. Some find that younger age groups are more willing to participate (Goyder 1986; Moore and Tarnai 2001), whereas others find the opposite (Singer et al. 1999), or no relation between age and participation at all (Etter and Perneger 1997). In their overview of age effects, Groves and Couper (1998) indicate that there is slightly more support for the assumption that the refusal rate is higher for the elderly, but that effective nonresponse is not necessarily lower. In multivariate tests, the effect might be inverse. They hypothesize that the elderly have more civic duty, which would make them participate more often, at least for governmental surveys. Regarding online surveys, studies show that younger age groups are more willing to respond than their older counterparts (Kwak and Radler 2002; Couper et al. 2007), although Dillman et al. (2009) point out that the youngest and oldest age groups are underrepresented and that the middle groups are the ones that are overrepresented. The difference between age groups is sometimes explained on the basis of differences in computer ownership, frequency of internet use and IT literacy. Although for paper-and-pencil-surveys there seems to be little empirical or theoretical evidence to suggest a correlation between age and survey participation, these reasons provide sufficient arguments to assume that older age groups participate less often in online surveys. However, those who participate in the pre-questionnaire demonstrate through their participation that they have a computer, internet and the necessary skills to use them. In addition, we expect the elderly to show a little more civic duty. We therefore expect older age groups to disproportionally drop out during the questionnaire phase $(\mathrm{H} 4 \mathrm{q})$, but once they have taken this step, there will be a selection effect, and that they therefore will drop out less than their younger counterparts during the diary phase of the fieldwork (H4d) due to higher levels of civic duty.

Along with those typical background variables that are often associated with nonresponse in survey research, lack of interest in the research topic, or behavior related to 
the topic is often considered a cause for nonresponse. This is generally seen as a major threat for the validity of sample surveys. For time use surveys specifically, it is often feared that they suffer from specific nonresponse related to the use of time. In her monumental book on the time use of women, Hochschild and Machung $(2003,287)$ state that: "Ironically, the women most burdened by the very crunch the researchers were investigating, probably didn't have time to fill out such a lengthy questionnaire." According to Knulst and Van den Broek (1998), respondents need approximately 80 minutes to fill in a seven-day diary. If one adds the time one needs to respond to a pre- and post-questionnaire besides the self-administered time diary, it becomes clear that the average response burden in time use surveys using a diary approach is higher compared to usual survey research. In the existing literature on nonresponse in time use surveys, it is thus often assumed that particularly busy people do not have the time to participate in lengthy time use surveys (Groves and Couper 1998; Van Ingen et al. 2008; Pääkkönen 1998; Knulst and Van den Broek 1998; Abraham et al. 2006). Zuzanek (1998, 547) explicitly counters this reasoning by stating that: "busy people find time for all sorts of things, and are more likely to respond to time-diary questionnaires". A literature review of former studies finds empirical support for both perspectives. Whether or not they find an association between nonresponse and busyness seems to be dependent on the indicator used. Knulst and van den Broek (1998) measured busyness based on objective indicators as, for example, the time spent in work and other obligations, as do Abraham et al. (2006). Abraham et al. (2006) conclude that objective busyness does not have a major influence on response rates, based on the findings that full-time workers have higher response rates than part-time employees. They also find that people who work more than full-time have the same rates as people who work part-time (see also Pääkkönen 1998). In the Abraham et al. study, all groups have a higher response rate than people who do not work at all. This last finding is replicated by Knulst and van den Broek (1998). They find that the least busy groups are the most underrepresented, and conclude from this finding that the relation between being busy and response is somewhat surprising: busy people participate more often than people who are less busy.

Pääkkönen (1998) and Van Ingen et al. (2008) show that, using subjective indicators, busyness has no influence on the participation rate. In the research carried out by Pääkkönen (1998), respondents were asked whether or not they were in such a hurry that they did not manage to do everything they had to do and whether they had to give up things during regular weekdays because they did not have enough time before filling out the time diary. Both indicators of subjective busyness did not influence the willingness to participate in the time diary. Stress symptoms only had a minor negative effect on the participation rates of the diary in that study. The study carried out by Van Ingen et al. (2008) investigated the effect of the feeling of being in a rush, but did not find such an effect of this on participation either.

Based on these findings, we expect that busyness in objective terms is positively related to participation. We hypothesize that busy people, such as the self-employed and full-time employees, have a lower dropout than their less busy counterparts, both during the questionnaire phase $(\mathrm{H} 5 \mathrm{q})$ and the diary phase $(\mathrm{H} 5 \mathrm{~d})$.

In addition to busyness, there are also other time-related factors that can have an effect on nonresponse. Nonresponse literature often focuses on the relationship between 
Table 1. The hypotheses summarized

\section{Timing}

Two different phases of dropout exist: 1) before filling in the questionnaire;

2) when completing the time diary

\section{Education}

The low educated will have a lower response rate on the questionnaire than their higher educated counterparts

There will be no additional dropout from the lower educated during the diary phase

\section{Gender}

Dropout of women is lower than the dropout of men during the questionnaire phase

Dropout of women is lower than the dropout of men during the diary phase

Age

Older age groups will disproportionally drop out during the questionnaire phase

Older age groups will dropout less than their younger counterparts during the diary phase

\section{Busyness}

Busy people have a lower dropout than their less busy counterpart during the questionnaire phase

Busy people have a lower dropout than their less busy counterpart during the diary phase

\section{Deviating time patterns}

People wo deviate significantly in their use of time from the standard will be overrepresented in the questionnaire phase

People who deviate significantly in their use of time will be more inclined to continue to participate during the diary phase

response and interest in the research topic or topic salience (Marcus et al. 2007; Van Kenhove et al. 2000). Health surveys, for example, consistently report troublesome differences between participants and non-participants in health behavior (Boström et al. 1993; Smith and Nutbeam 1990; Hill et al. 1997) and the use of health services (Etter and Perneger 1997). Respondents with a specific profile and/or interest in the outcome of the study are often more willing to participate. This, of course, can cause problematic nonresponse bias when people who are interested have other attributes on the research topic than those with no interest. For time use surveys, this could mean that people who are aware that their time use differs from standard patterns, are more willing to respond. The reason would be that these people wish to be heard, that their deviant patterns are included in the figures. Therefore, we hypothesize that people who deviate significantly in their use of time from the standard will be overrepresented in the questionnaire phase (H6q) and will be more inclined to continue to participate during the diary phase and therefore have a lower dropout (H6d). All formulated hypotheses are summarized in Table 1.

\section{Used Data Files}

Before we go further into detail about our research design, we first describe the data and field work procedures in order to perform the nonresponse analysis. We make use of two different data sets. 


\subsection{TOR13}

TOR13 is an OTUS that was conducted in 2013 and 2014 (Minnen et al. 2014). One of the objectives of TOR13 was to collect time use data by means of an innovative and costsaving software platform that was developed inhouse. The goal was to replace paper-andpencil methodology with a cost-reducing online methodology, and to test the functionality of the software platform. One of the greater savings was achieved by the introduction of automated fieldwork processes, and so the elimination of interviewers. In earlier time use surveys, the role of the interviewer was to convince respondents to participate, assist respondents with problems and register activities. In this study, this role was partly taken over by a web app that could be accessed via the browser. Convincing respondents to participate was done by letter. Invitations were sent out by post every two weeks in order to achieve a good distribution over a whole calendar year. If a respondent did not log in two weeks after sending out the invitation, a first reminder was sent. A second and last reminder was sent four weeks after the invitation. In case respondents had questions or needed help, this was only offered by email and telephone. The method made it possible to reduce the costs per respondent from EUR 260 to EUR 60-80. In total, a random sample of 39,756 people between 18 and 75 years living in Flanders (the Dutch-speaking part of Belgium) and Brussels (only Dutch-speakers were invited) was selected from the Belgian National Register with equal probabilities of being chosen. They were asked to complete a pre-questionnaire, keep a time diary for seven consecutive days and complete a postquestionnaire. In order to participate, one had to log in (using a username and password that were communicated via the letter) on a website where more information on the research project was offered and where they could start their participation. Those who did finish the research completely, automatically took part in a lottery where they could win different cash prizes with the maximum prize of EUR 500.

For 124 respondents, the gender and/or year of birth differed from the data in the national register. We consider this an indicator that a person other than the sampled person completed the questionnaire. For the analyses in this contribution, these people are excluded, since they were technically not sampled to participate in this study. Response rates will be discussed in detail in the results section of this contribution.

\subsection{Labour Force Survey 2013}

To evaluate the nonresponse bias on the TOR13 time use survey, we made use of the Belgian subsample of the Labour Force Survey (LFS). The LFS is an obligatory face-toface survey of members of Belgian households that are at least 15 years old. Refusal is punished by law with a fine of EUR 40 to EUR 200. Despite its obligatory nature, this survey also suffers from some nonresponse due to inability to participate (for example, in the case of illness). Nevertheless, these data are generally known as the least bad option if one wishes to compare a sample with the total Belgian population and are therefore often used for this purpose. This study ran completely simultaneously with the TOR13 survey.

Despite the many similarities, some data operations are needed to make the data comparable. We restrict the research population of the LFS solely to the 18 to 75 years old inhabitants of Flanders $(n=37,828)$, in order to make the population comparable with that of the TOR13. The LFS does not allow making a distinction between Dutch- and 
French-speaking Brusselians. Therefore, and because of the existing large differences in socioeconomic and cultural background between the Dutch- and French-speakers in Brussels, we decided to eliminate the Dutch-speaking inhabitants of Brussels from the TOR13 sample. After these data processings, the research populations can be considered as completely similar. The respondents analyzed in this study are thus residents of the Flemish Region between the ages of 18 and 75, all of whom were drawn individually on the basis of a random sample. A total of 36,665 sampled individuals (92.2\%) of the TOR13 sample met these criteria.

\section{Design}

To check selective nonresponse and representativeness, we first use methods that come from demography and medical sciences. First, we use a life table (i.e., a mortality table)(Singer and Willett 2003, chap. 10) to determine at what point in the survey process respondents drop out. The sample population and the dropout rate during the survey process are very similar to a population and mortality in a life table. In the life table we will treat dropout as mortality. Different research phases are equated with reaching a certain age. More specifically, eleven research phases are taken into consideration: invitation, prequestionnaire started, pre-questionnaire finished, logging at least one activity, logging one day, two days, three days, four days, five days, six days and finishing the time diary. Based on this table, we can then calculate the dropout probability in any particular phase in the research, as well as the cumulative survival.

Second, we will combine those methods with more regular approaches to analyse nonresponse. Porter and Whitcomb (2005) (see also Johnson and Wislar 2012), identify four such methods:

1. by comparing the response with other data sources,

2. by comparing panel respondents of a successive survey with respondents of a base survey,

3. by means of a nonresponse follow-up survey, and

4. by time of response analysis.

In this article, we will make use of the first two methods.

In order to map the selective nonresponse prior to the completion of the preliminary questionnaire, we will (by absence of own data at this point) compare the response on the pre-questionnaire with that of the Flemish subset of the Labour Force Survey 2013. Because of the many similarities between the two data sets, as mentioned earlier, this source offers the best available data for comparing the research population with the sampled population. We will use this method to analyze the nonresponse during the prequestionnaire part of the survey. The two data sets will be compared using ratio weights, based on post stratification class adjustments. These are calculated as:

$$
\text { Ratio weights }=\frac{\text { realized sample }(\text { TOR } 13) \text { in } \%}{\text { population }(\text { LFS13) in } \%}
$$

Weights higher than 1 indicate underrepresentation of the concerned subgroup in the TOR13 data, whereas weights below 1 indicate overrepresentation. 
For the selective nonresponse in later stages of the fieldwork after finishing the prequestionnaire, we will apply the method of comparing the base survey (i.e., the prequestionnaire) to later stages (Porter and Whitcomb 2005; Johnson and Wislar 2012). For this, we fall back on the previously identified research phases. Because we can only rely on data from respondents who completed the questionnaire, eight research phases remain: finishing the pre-questionnaire (0), logging 1 activity (1), logging 1 day (2), 2 days (3), 3 days (4), 4 days (5), 5 days (6) and 6 days (7). By filling in the pre-questionnaire, respondents provided us with information on their background. For the nonresponse occurring during the time diary, we can thus execute a comparison between responders and non-responders on all those who finished the pre-questionnaire. We will do this using Discrete-Time Survival Analysis (Singer and Willet 2003, chap. 11 and 12). These analyses focus on describing whether and when events occur and whether or not differences can be observed in occurrence and timing to different covariates. For this, we will use standard logistic regression on a person-period data set. In a typical person data set, every person has one record or line of data, whereas in a person-period data set every person has multiple records. The exact amount of records is dependent on the periods that this person is at risk. For example, if someone drops out of the fieldwork in the third stage, the data set will have three records. In this case, the maximum amount of records is eight, since we take eight stages of the fieldwork into account. The indicator for time that will be used here is thus measured discretely. The event, or in other words the dependent variable, that is under investigation here is dropout, or, put differently, failing to finish the research.

\section{Covariates That Will Be Taken Into Account}

In order to analyze a potential selective nonresponse to the pre-questionnaire, we had to limit the categories per variable to the level of detail of the least detailed questionnaire. We use the following operationalization for the background variables: Gender (two categories: Male/Female), Age (five categories: 18 to 24 years/25 to 39 years/40 to 54 years/55 to 64 years/65 + years), and Education (three categories: ISCED 1 to 2 (low)/ISCED 3 to 4 (average)/ISCED 5 to 8 (high)).

In order to measure objective busyness, we rely on pre-questionnaire data concerning occupational status (six categories: working/unemployed/student/incapacitated/retired/ other) and full versus part-time employment (four categories: self-employed/fulltime/part-time/no contract) (i.e., Knulst and van den Broek 1998; Abraham, et al. 2006).

A deviating use of time will be measured using work schedule (five categories: Nonworking, Fixed shifts, Flexible shifts, and other), Evening and Night shifts (three categories: Never/occasionally, Regularly, Always/non-working). All of these variables were answered by most of the respondents, except the questions on evening and night shifts. They were part of an extra sub-questionnaire that only had to be filled in by a randomly selected subsample of the total population (this was done in order to reduce participation burden) and are thus only answered by a random $40 \%$ of the total sample population.

\section{Results}

The results will be discussed in the following order: first, we will present the exact timing and occurrence of dropout during the fieldwork. Second, we will present the comparison 
Table 2. Life table of the dropout during the TOR13-fieldwork

\begin{tabular}{|c|c|c|c|c|c|c|}
\hline $\begin{array}{l}\text { Status achieved } \\
\text { at the start } \\
\text { of the phase }\end{array}$ & $\begin{array}{r}\text { Number } \\
\text { Entering } \\
\text { Interval }\end{array}$ & Censored & $\begin{array}{r}\text { Dropout } \\
\text { (in } n)\end{array}$ & $\begin{array}{r}\text { Dropout } \\
\text { (in \%) }\end{array}$ & $\begin{array}{r}\text { Survival } \\
\text { (in \%) }\end{array}$ & $\begin{array}{r}\text { Cumulative } \\
\text { survival } \\
\text { (in \%) }\end{array}$ \\
\hline Invite & 36,665 & 0 & 24,768 & 67.6 & 34.4 & 34.4 \\
\hline $\begin{array}{l}\text { Pre-questionnaire } \\
\text { started }\end{array}$ & 11,897 & 0 & 776 & 6.5 & 93.5 & 30.3 \\
\hline $\begin{array}{l}\text { Pre-questionnaire } \\
\text { finished }\end{array}$ & 11,121 & 0 & 4,427 & 39.8 & 60.2 & 18.3 \\
\hline 1 activity logged & 6,694 & 0 & 2,106 & 31.5 & 68.5 & 12.5 \\
\hline 1 day logged & 4,588 & 0 & 445 & 9.7 & 90.3 & 11.3 \\
\hline 2 days logged & 4,143 & 0 & 204 & 4.9 & 95.1 & 10.7 \\
\hline 3 days logged & 3,939 & 0 & 150 & 3.8 & 96.2 & 10.3 \\
\hline 4 days logged & 3,789 & 0 & 121 & 3.2 & 96.8 & 10.0 \\
\hline 5 days logged & 3,668 & 0 & 98 & 2.7 & 97.3 & 9.7 \\
\hline 6 days logged & 3,570 & 3,428 & 142 & 4.0 & 96.0 & 9.3 \\
\hline
\end{tabular}

between responders on the pre-questionnaire and the LFS13. Last, the analyses of dropout of all those who finished the pre-questionnaire in later stages of the fieldwork will be shown using discrete-time survival analyses.

\subsection{The Occurrence and Timing of Nonresponse}

Table 2 shows the dropout during the different phases of the TOR13 fieldwork. There are a number of times when the dropout is high. Nearly seven in ten of the initial sample drop out before the questionnaire is completed, because they do not respond to the invite, or do not finish the pre-questionnaire. During the diary phase, another part of the original sample drops out. The data thus show support for H1. That being said, the actual situation is more complex than described in H1. The majority of the original sample fall out before the questionnaire has started, and the diary phase consists of several phases that lead to dropout. The most important dropout during the diary phase occurs when the first activity and the first day are registered, only then does it gradually decrease. In the next section, we will investigate to what extent this dropout is selective. We do this not only by making a distinction between the questionnaire phase and the diary phase. We will also consider the different phases of the diary stage when checking for selectivity in dropout. However, we will first discuss the selectivity of the $69.7 \%$ who drop out before finishing the questionnaire.

\section{2. $\quad$ Nonresponse in the Pre-Questionnaire Phase}

The selectivity of the dropout prior to the diary phase is analyzed by using a comparison with the mandatory Labour Force Survey 2013 (see Table 3. The ratios in the TOR13 data are calculated on the entire population living in Flanders who completed the preliminary questionnaire $(\mathrm{n}=11,121)$, while the ratios in the LFS 2013 are calculated on all 18 to 75-year-old residents of Flanders who participated $(n=37,828)$ A weighting coefficient higher than 1 indicates an underrepresentation in the TOR13 data, whereas a coefficient lower than 1 indicates an overrepresentation of the subpopulation in question. 
Table 3. Composition of the population. the realized sample for the pre-questionnaire and the ratio weights

\begin{tabular}{|c|c|c|c|c|}
\hline & & $\begin{array}{l}\text { Population } \\
\text { in \%* } \\
\text { (LFS13) } \\
\quad \text { [CI 95\%] }\end{array}$ & $\begin{array}{l}\text { Realized } \\
\text { sample in \%* } \\
\text { (TOR13) } \\
\quad \text { [CI 95\%] }\end{array}$ & $\begin{array}{l}\text { Ratio } \\
\text { weights }\end{array}$ \\
\hline \multicolumn{5}{|l|}{ Gender } \\
\hline & Female & $50.5[50.0-51.0]$ & $53.0[52.1-53.9]$ & 0.95 \\
\hline & Male & $49.5[49.0-50.0]$ & $47.0[46.1-47.9]$ & 1.05 \\
\hline \multicolumn{5}{|l|}{ Age } \\
\hline & 18 to 24 years & $11.1[10.8-11.4]$ & $13.4[12.8-14.0]$ & 0.83 \\
\hline & 25 to 39 years & $22.6[22.2-23.0]$ & 26.1 [25.3-26.9] & 0.87 \\
\hline & 40 to 54 years & 30.4 [29.9-30.9] & $31.3[30.4-32.2]$ & 0.97 \\
\hline & 55 to 64 years & $18.8[18.4-19.2]$ & $18.7[18.0-19.4]$ & 1.01 \\
\hline & $65+$ years & $17.0[16.6-17.4]$ & $10.5[9.9-11.1]$ & 1.62 \\
\hline \multicolumn{5}{|l|}{ Education } \\
\hline & $\begin{array}{l}\text { Low (ISCED } \\
1 \text { to } 2 \text { ) }\end{array}$ & 29.7 [29.2-30.2] & $22.2[21.4-23.0]$ & 1.34 \\
\hline & $\begin{array}{l}\text { Average (ISCED } \\
3 \text { to } 4 \text { ) }\end{array}$ & 39.7 [39.2-40.2] & 35.9 [35.0-36.8] & 1.11 \\
\hline & $\begin{array}{l}\text { High (ISCED } \\
5 \text { to } 8 \text { ) }\end{array}$ & $30.6[30.1-31.1]$ & 41.9 [41.0-42.8] & 0.73 \\
\hline \multicolumn{5}{|l|}{$\begin{array}{l}\text { Occupational } \\
\text { status }\end{array}$} \\
\hline & Working & 56.4 [55.9-56.9] & $64.7[63.8-65.6]$ & 0.87 \\
\hline & Unemployed & $4.6[4.4-4.8]$ & $3.6[3.3-3.9]$ & 1.28 \\
\hline & Student & $6.3[6.1-6.5]$ & $9.1[8.6-9.6]$ & 0.69 \\
\hline & Incapacitated & $4.9[4.7-5.1]$ & $2.1[1.8-2.4]$ & 2.33 \\
\hline & Retired & $22.2[21.8-22.6]$ & $17.0[16.3-17.7]$ & 1.31 \\
\hline & Other & $5.6[5.4-5.8]$ & $3.5[3.2-3.8]$ & 1.60 \\
\hline \multicolumn{5}{|l|}{$\begin{array}{r}\text { Full/part-time } \\
\text { employment }\end{array}$} \\
\hline & Non-working & 43.4 [42.9-43.9] & 35.5 [34.6-36.4] & 1.22 \\
\hline & Self-employed & 9.0 [8.7-9.3] & $7.5[7.0-8.0]$ & 1.20 \\
\hline & Full-time & $34.3[33.8-34.8]$ & $42.6[41.743 .5]$ & 0.81 \\
\hline & Part-time & $13.3[13.0-13.6]$ & $14.4[13.7-15.1]$ & 0.92 \\
\hline \multicolumn{5}{|l|}{ Work schedule } \\
\hline & Non-working & 44.4 [43.9-44.9] & $36.4[35.5-37.3]$ & 1.22 \\
\hline & Fixed schedule & $39.3[38.8-39.8]$ & $24.4[23.6-25.2]$ & 1.61 \\
\hline & Flexible schedule & $13.5[13.2-13.8]$ & $36.0[35.1-36.9]$ & 0.38 \\
\hline & Other schedule & $2.8[2.6-3.0]$ & $3.3[3.0-3.6]$ & 0.85 \\
\hline \multicolumn{5}{|l|}{ Evening shifts } \\
\hline & Non-working & 44.4 [43.9-44.9] & $36.5[34.9-38.1]$ & 1.22 \\
\hline & Never & $35.9[35.4-36.4]$ & $24.6[23.2-26.0]$ & 1.46 \\
\hline & $\begin{array}{l}\text { Occasionally/ } \\
\text { regularly/always }\end{array}$ & $19.7[19.3-20.1]$ & $38.9[37.3-40.5]$ & 0.51 \\
\hline \multicolumn{5}{|l|}{ Night shifts } \\
\hline & Non-working & 44.4 [43.9-44.9] & $36.5[34.9-38.1]$ & 1.22 \\
\hline & Never & 49.1 [48.6-49.6] & $45.9[44.3-47.5]$ & 1.07 \\
\hline & $\begin{array}{l}\text { Occasionally/ } \\
\text { regularly/always }\end{array}$ & $6.6[6.3-6.9]$ & $17.6[16.4-18.8]$ & 0.38 \\
\hline
\end{tabular}


The different age groups show some selective nonresponse bias. In general, we find that the lower the age, the better the chance of participation. Up to the age of 54, we see an overrepresentation in the data, while groups from the age of 55 are underrepresented in the sample population. From the age of 65 or older, the underrepresentation becomes even larger. This is possibly a result of the online setup of the survey instrument. This age group is known for having less ICT competences and a lower accessibility to internet connections. All other age groups are somewhat overrepresented in the sample. Therefore, we consider $\mathrm{H} 4 \mathrm{q}$ not rejected.

Rather large differences in participation in the pre-questionnaire are also found between the educational classes. The results show that the higher the level of education, the higher the final participation will be. The higher educated are strongly overrepresented, whereas the lower educated are underrepresented. People with an average level of education are only slightly underrepresented. This finding is in accordance with $\mathrm{H} 2 \mathrm{q}$.

Based on occupational status, we find that, consistent with findings on nonresponse bias in usual survey research, the incapacitated are strongly underrepresented. Also, retirees and unemployed persons are a little underrepresented. Furthermore, we find that students, and to a smaller extent people who are working, are rather overrepresented. The full/parttime employment divide leads to minor differences in response. Both people working on a full-time basis and on a part-time basis are overrepresented. This is not surprising because both form a large part of the group that are currently employed, that we have previously seen as being overrepresented. Although the differences are small, we see that people who work part-time are slightly less likely to participate in the OTUS than people who work full-time. The self-employed, a category that cannot be put in either the full or part-time categories, are slightly underrepresented. We consider these findings as more complex than $\mathrm{H} 5 \mathrm{q}$ suggests, namely that normally busy people do indeed participate slightly more often than people with a lower or no work-related time pressure, but that this does not apply to the very busiest, in this contribution the self-employed.

The response differs based on the kind of work schedule of the respondent. The largest share of the population, people with a fixed working schedule, are somewhat underrepresented, whereas people with flexible hours (working in shifts, those who have a flexible schedule or an intermittent schedule) are overrepresented in our survey sample compared to the total Belgian population. The same holds for people who work evening and night shifts. These groups are strongly overrepresented in the sample. These findings thus show full support for H6q, namely that people with deviating, non-standard working hours do indeed seem to participate more often in a questionnaire about time use.

Lastly, small differences in participation on the pre-questionnaire between men and women were found. Hence, we consider $\mathrm{H} 3 \mathrm{q}$ as not refuted.

\subsection{Nonresponse in Later Stages of the Survey}

After filling in the pre-questionnaire, respondents should start with keeping the seven-day diary. In this part, we can rely on data that were reported by the respondents themselves during the pre-questionnaire. Models $1 \mathrm{a}$ and 1b in Table 4 show the analyses on the complete subsample of those who filled in the pre-questionnaire. In order to cope with the problem that only a random $40 \%$ of the sample filled in the questions on evening and night shifts, we show 


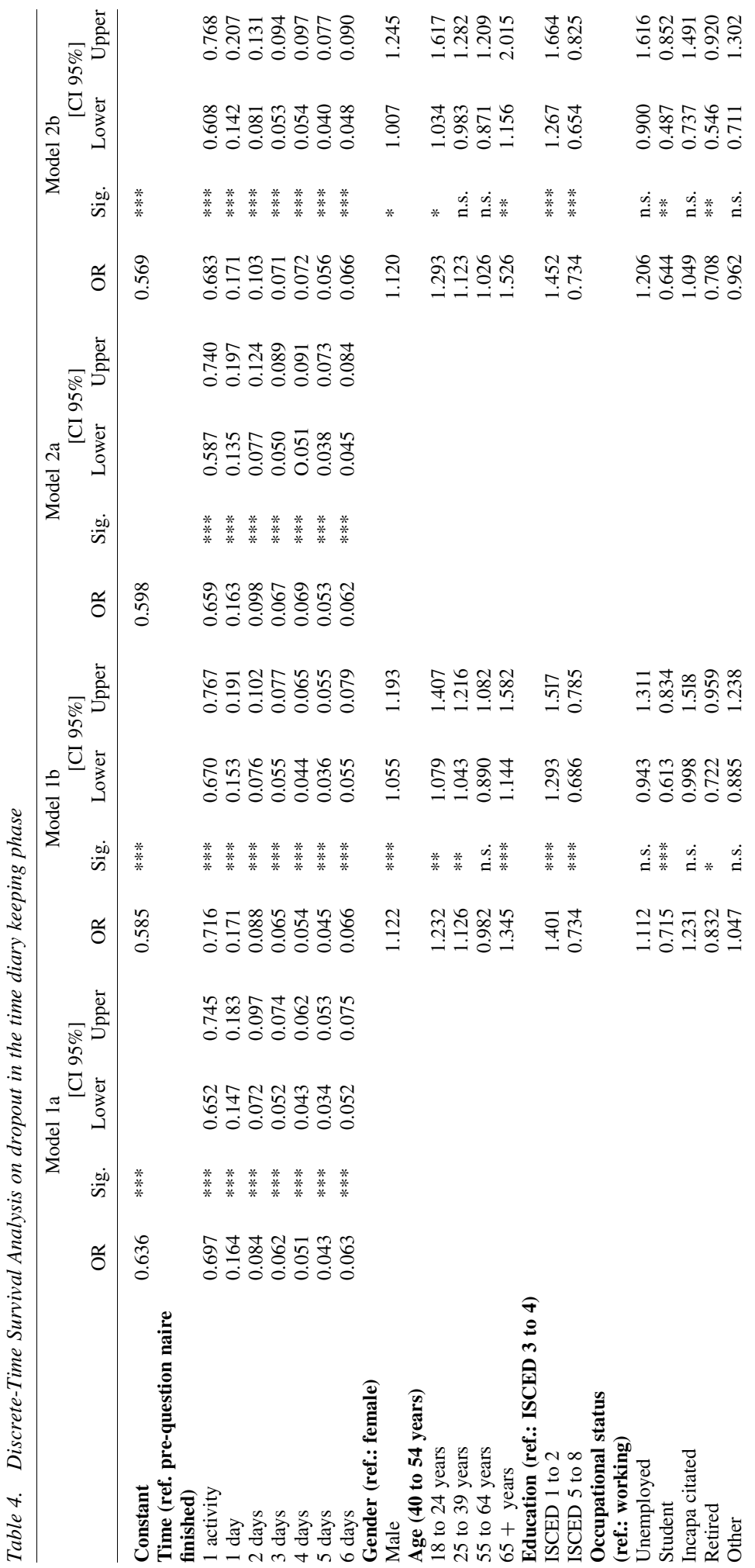




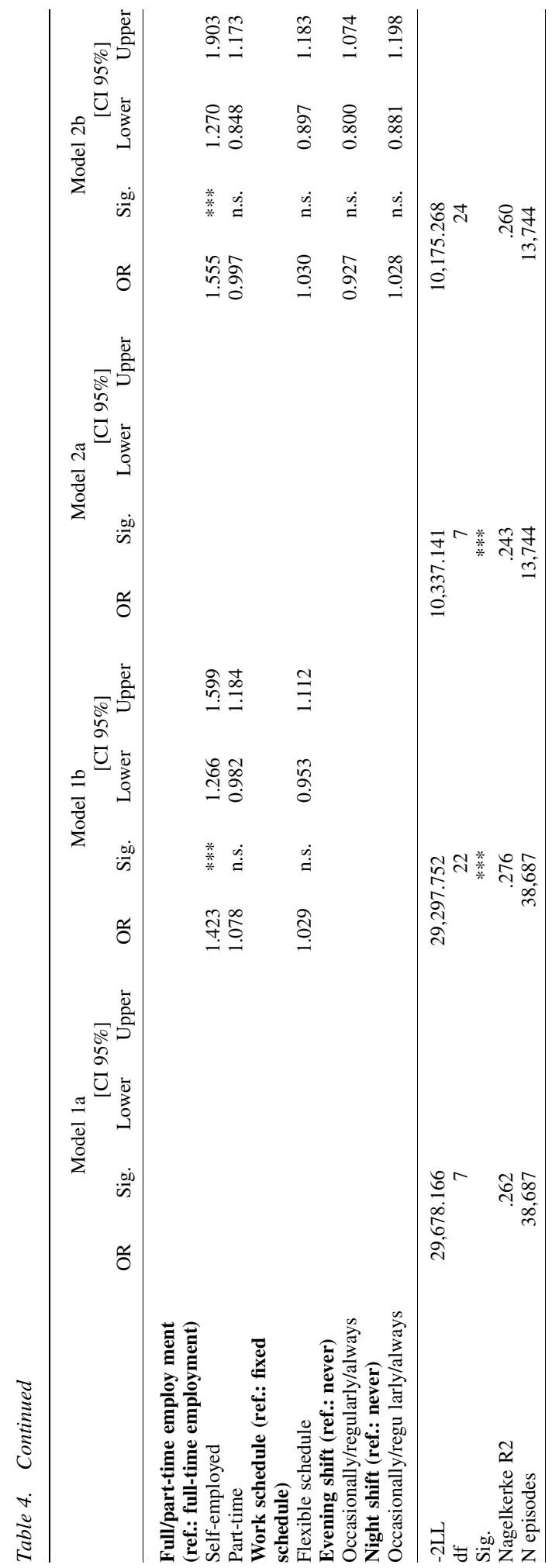


the analyses of those variables separately in models $2 \mathrm{a}$ and $2 \mathrm{~b}$. The time indicators bear the name of the initial status. For example, the " 1 day" indicator shows the odds ratio (OR) on which someone drops out in the interval between one and two days logged.

In this part, due to a lack of space, we only show the analyses about the effect of the different covariates on dropout during the entire diary phase to test our hypotheses. As was previously made clear, however, the relation between dropout and the covariates during the diary phase can differ from phase to phase. The models that take this into consideration, in which interactions between the time indicators and the covariates are included, would take up too much space and can thus be found in Supplemental data. Where they provide useful insights, they will be discussed below.

Models 1a and 2a show the plain effect of time on nonresponse. We do not go into detail on those effects, because they are already discussed in a clear way using the life table analysis. Model 1b shows a better fit than its predecessor, indicating that the covariates offer additional explanation power for the chances of a dropout. This can be seen as an indicator that selective nonresponse also occurs in the diary phase.

Men are 1.122 times more likely than women to drop out during the diary phase. These results can be considered as supportive for $\mathrm{H} 3 \mathrm{~d}$. The interaction terms (see Supplemental data online, Table 1) show that this difference mainly occurs in the starting phases of the diary. The differences are largest before one activity was registered $(\mathrm{OR}=1,266)$. The difference then gradually decreases. After three days have been registered, there is no longer a difference in dropout between the genders.

Regarding age, the results show that both the youngest groups (up to 39 years) and the oldest group $(65+)$ have a higher dropout during the diary phase than the 40 to 64 -yearolds. The dropout is highest among the over-65s $(\mathrm{OR}=1.345)$, followed by the 18 to $24-$ year-olds $(\mathrm{OR}=1.232)$ and the 25 to 39 -year-olds $(\mathrm{OR}=1.126)$. H4d can thus neither be accepted nor rejected. The middle age groups clearly drop out the least. The interaction effects, however, between time and age show interesting differences. The oldest age group who already dropped out excessively during the questionnaire, and who it was suspected would drop out less often during the diary phase, experience a high dropout during the first phases of the diary. The previously described selection effect only takes place after these respondents have demonstrated that they can handle the diaries by filling in at least one activity. This is different for younger age groups (up to 39 years old). They take the first hurdle more easily (registering the first activity) and then drop out more often during the first, second, third and fourth day of the fieldwork (see Supplemental data online, Table 2). It remains unclear why they dropout later. It is possible that this group will drop out due to the repetitive nature of a time use survey.

The models also show fairly large differences in dropout between the low and highly education. The lower educated dropout more often than the middle educated $(\mathrm{OR}=1.401)$, while highly educated have a lower odds ratio $(\mathrm{OR}=0.734) . \mathrm{H} 2 \mathrm{~d}$ thus has to be clearly refuted. The interaction effects show that, here too (Supplemental data online, Table 3), the effects are greatest at the start of the diary phase. It appears that primarily people with a low level of education drop out before completing the first activity and the first day. During the later days, this difference between the educational groups will gradually decrease. 
Regarding professional status, we see no major differences in dropout between the working, the unemployed, the incapacitated and others. We do, however, observe differences with students $(\mathrm{OR}=0.715)$ and the retired $(\mathrm{OR}=0.832)$. Both groups have a lower dropout during the diary phase than the others. The interaction effects for the retired show the same pattern as those for the oldest age group (see Supplemental data online, Table 4). They dropout before completing the first activity, after which the differences become smaller. Ultimately, they will thus drop out less than the other groups. The incapacitated persons also experienced problems with the registration of the first activity. Unlike the retired persons, the participation of this group does not seem to improve significantly after they have taken this first hurdle. As a result, their final dropout will be slightly higher than that of the other occupational groups (see Supplemental data online, Table 4, model 2). When controlled for other variables, this difference vanishes. The lower dropout rate among students mainly occurs at the start of the diary phase and they come more often than others through the phase in which the first activity must be registered. Only during the fourth day of registration is their dropout slightly higher than for other groups. Based on the number of hours worked, we see no difference between part-time and full-time workers. It is clear, however, that the self-employed drop out more often than people in paid employment. This difference only occurs during the registration of the first activity, in which the self-employed drop out more often. Based on these findings, it is impossible to assume that busy groups will drop out less during the diary phase. Therefore, we also reject H5d. Non-working people do not differ so much from working people in terms of dropout. No differences were found either between full-time or part-time workers. However, it is found that retirees (even checked for age) drop out less often and that the self-employed drop out more often. Specifically for the diary phase, these findings indicate that people with a busy work schedule have a slightly higher dropout rate than people with a quieter work schedule. This finding, however, should be further investigated.

No differences were found in dropout based on work schedule and whether or not evening and night shifts work (see model 2b). These results can be considered as supportive for H6d, which states that people with a deviant work schedule do not drop out more or less frequently than people with a more regular work schedule.

\section{Discussion}

In this contribution, we examined both the timing of dropping out, and the selectivity thereof in online time use surveys using a diary approach. By making use of methods such as life tables and discrete-time survival analysis, where dropout is considered the transition that someone (preferably not) encounters during the duration of a complete time use survey using diaries, we found that timing of dropout is related to selectivity of this dropout. Different groups show different behavior during the course of the study. Their dropout varies, not only in the final result, but also in the exact timing.

The results showed that there are two (or, depending on the definition, three) major moments of dropout during the course of a typical online diary research. The largest dropout occurs before one question has been answered. In that respect, time use research is no different than normal surveys. Almost $68 \%$ of the invited respondents dropped out before starting the questionnaire. What may be different in this study, however, is the reason for 
dropping out. These dropouts include not only people who do not wish to participate, but also people who do not have internet access or the necessary IT competences to participate in an online study. Two other major hurdles where many respondents dropped out were the phases in which respondents had to fill in the first activity and the first day, both at the very start of the diary phase. After that, dropout decreases steadily.

Moreover, the phases in which dropout mainly occurs show a selective dropout. The selectivity on the questionnaire leads to a first underrepresentation of over-65s and the low and middle-educated, very similar to the results that were found by Dillman et al. (2009). In addition, we found that men, the self-employed, non-working persons, such as unemployed persons, incapacitated persons and retired persons are underrepresented in this phase. Also noteworthy is the overrepresentation of people who have a flexible work schedule and of those who work evening and night shifts.

Where normal survey research generally ends after the questionnaire, the second and arguably the most important part of the time use survey begins. This second phase, especially the start of it, leads to an additional dropout of the subsample that finished the questionnaire. This dropout is also selective. To a large extent, this selectivity is in the same direction as with regard to the selectivity on the questionnaire. An additional group of men drop out extra often, just like the over-65s, the lower educated and the selfemployed. Groups such as the unemployed and the incapacitated participate less in the questionnaire, but once they do participate, they do not show additional dropout.

With regard to the interaction between timing and selectivity, it is noticeable that a high degree of selective dropout occurs especially during the first two days of the diary keeping. For example, it turns out that mainly over-65s, the retired, the incapacitated and the self-employed often fall out disproportionately while completing the first activity and the first two days. A seven-day diary therefore does not lead to extra selectivity compared to a two-day diary.

The specific nonresponse at the start of the diary phase should thus deserve attention in future time use surveys using a diary approach. The elderly, the retired and the incapacitated may be groups that need additional help with the first steps in which the diary is completed. In other surveys, this is where the interviewer steps in. Possibly, an interviewer is able to lower the dropout of those subpopulations. This may also apply to the self-employed, but it seems more likely that they will drop out as soon as they experience the high level of participation burden. To counteract this selectivity in dropout, consideration can be given to motivating this group extra by responding to their specific use of time, as well as offering them (higher) compensation for their time loss. However, we expect that it would be more effective, not only for this group, but for all participants, to structurally reduce the participation burden typical of time use surveys.

For this, we expect a lot from the shift from web surveys to surveys on mobile devices. Before the introduction of the web survey, respondents were given a paper diary that they could fill in at any time of the day. This changed at the introduction of the web survey where people had to have a computer (and internet connection) at their disposal, which replaced direct registration with retrospective registration (usually during the evening), and, in turn, increased the response burden, because of the effort to reconstruct the day. The introduction of registration via mobile devices again makes it possible to actively fill in a diary at any time. Besides, it offers possibilities for imputing diaries with passive data (from smartphones, watches, etc.), leading to further reduction of the participation burden. This 
could also help to counter the slightly higher dropout rates of groups with high IT competences (such as students in this study) during later phases of the fieldwork. They may drop out due to the higher degree of repetition of the diaries. Own recent, unpublished, research shows that people nowadays often use a combination of devices for their participation. Future research will have to clarify how this shift affects representativeness.

Furthermore, future research about nonresponse in surveys should make clear to what extent the selective dropout leads to bias on time use parameters. Hence it is necessary, certainly for time use surveys, to create clarity about the relationship between busyness and dropout. Another research track that should be followed is how dropout can be prevented at the different identified hurdles by improving the research methodology.

\section{References}

Abraham, K.G., A. Maitland, and S.M. Bianchi. 2006. "Nonresponse in the American Time Use Survey: Who Is Missing from the Data and How Much Does It Matter?" Public Opinion Quarterly 70(5): 676-703. DOI: https://doi.org/10.1093/poq/nfl037. Bethlehem, J. 2009. "The Rise of Survey Sampling." Statistics Netherlands. Discussion Paper (09015). Available at: https://www.cbs.nl/-/media/imported/documents/2009/07/ 2009-15-x10-pub.pdf?la $=$ nl-nl\&hash $=$ B75A64DF0877B7FD089E796FCFE 81145 (accessed August 2020).

Boström, G., J. Hallqvist, B.J.A. Haglund, A. Romelsjö, L. Svanström, and F. Diderichsen. 1993. "Socioeconomic Differences in Smoking in an Urban Swedish Population. The Bias Introduced by Non-Participation in a Mailed Questionnaire." Scandinavian Journal of Public Health 21(2): 77-82. DOI: https://doi.org/10.1177/1403494893021 00204.

Connelly, N.A., T.L. Brown, and D.J. Decker. 2003. "Factors Affecting Response Rates to Natural Resource - Focused Mail Surveys: Empirical Evidence of Declining Rates Over Time." Society \& Natural Resources 16(6): 541-549. DOI: https://doi.org/10. 1080/08941920309152.

Couper, M.P., A. Kapteyn, M. Schonlau, and J. Winter. 2007. "Noncoverage and Nonresponse in an Internet Survey." Social Science Research 36(1): 131-148. DOI: https://doi.org/10.1016/j.ssresearch.2005.10.002.

Cull, W.L., K.G.O. Connor, S. Sharp, and S.S. Tang. 2005. "Methods Response Rates and Response Bias for 50 Surveys of Pediatricians." HSR: Health Services Research 40(1): 213-226. DOI: https://doi.org/10.1111/j.1475-6773.2005.00350.x.

Curtin, R., S. Presser, and E. Singer. 2000. "The Effects of Response Rate Changes on the Index of Consumer Sentiment." Public Opinion Quarterly 64(4): 413-428. DOI: https://doi.org/10.1086/318638.

Dillman, D.A., G. Phelps, R. Tortora, K. Swift, J. Kohrell, J. Berck, and B.L. Messer. 2009. "Response rate and measurement differences in mixed-mode surveys using mail, telephone, interactive voice response (IVR) and the Internet." Social Science Research, 38(1), 1-18. DOI: https://doi.org/10.1016/j.ssresearch.2008.03.007.

Etter, J.-F., and T.V. Perneger. 1997. "Analysis of Non-Response Bias in a Mailed Health Survey." Journal of Clinical Epidemiology 50(10): 1123-1128. DOI: https://doi. org/10.1016/S0895-4356(97)00166-2. 
Goyder, J. 1986. "Surveys on Surveys: Limitations and Potentialities." Public Opinion Quarterly 50(1): 27-41. DOI: https://doi.org/10.1086/268957.

Goyder, J., K. Warriner, and S. Miller. 2002. "Evaluating Socio-Economic Status (SES) Bias in Survey Nonresponse.” Journal of Official Statistics 18(1): 1-11. Available at: https://www.scb.se/contentassets/ca21efb41fee47d293bbee5bf7be7fb3/evaluatingsocio-economic-status-ses-bias-in-survey-nonresponse.pdf (accessed September 2020). Groves, R.M., and M.P. Couper. 1998. Nonresponse in Household Interview Surveys. New York (NY): John Wiley. DOI: https://doi.org/10.1525/aa.1999.101.3.699.

Hill, A., J. Roberts, P. Ewings, and D. Gunnell. 1997. "Non-Response Bias in a Lifestyle Survey." Journal of Public Health 19(2): 203-207. DOI: https://doi.org/10.1093/ oxfordjournals.pubmed.a024610.

Hochschild, A., and A. Machung. 2003. The Second Shift: Working Families and the Revolution at Home. New York (NY): Penguin.

Johnson, T.P., and J.S. Wislar. 2012. "Response Rates and Nonresponse Errors in Surveys." JAMA: The Journal of the American Medical Association 307(17): 1805-1806. DOI: https://doi.org/10.1001/jama.2012.3532.

Knulst, W., and A. van den Broek. 1998. "Do Time-Use Surveys Succeed in Measuring 'Busyness'? Some Observations of the Dutch Case." Loisir et Société / Society and Leisure 21(2): 563-572. DOI: https://doi.org/10.1080/07053436.1998.10753671.

Kwak, N., and B. Radler. 2002. "A Comparison Between Mail and Web Surveys: Response Pattern, Respondent Profile, and Data Quality.” Journal of Official Statistics 18(2): 257-273. Available at: https://www.scb.se/contentassets/ca21efb41fee47d293bbee5bf7be7fb3/a-comparison-between-mail-and-web-surveys-response-patternrespondent-profile-and-data-quality.pdf (accessed September 2020).

Marcus, B., M. Bosnjak, S. Lindner, S. Pilischenko, and A. Schutz. 2007. "Compensating for Low Topic Interest and Long Surveys: A Field Experiment on Nonresponse in Web Surveys." Social Science Computer Review 25(3): 372-383. DOI: https://doi.org/10. 1177/0894439307297606.

Minnen, J., I. Glorieux, T.P. van Tienoven, D. Weenas, J. Deyaert, S. van den Bogaert, and S. Rymenants. 2014. "Modular Online Time Use Survey (MOTUS) - Translating an existing method in the 21st century." Electronic International Journal of Time Use Research, 11(1), 73-93. DOI: https://doi.org/10.13085/eIJTUR.11.1.73-93.

Moore, D.L., and J. Tarnai. 2001. "Evaluating Nonresponse Error in Mail Surveys." In Survey Nonresponse, edited by R.M. Groves, D.A. Dillman, J.L. Eltinge, and R.J.A. Little, 197-212. New York (NY): Wiley.

Pääkkönen, H. 1998. "Are Busy People Under- or over-Represented in National Time Budget Surveys?” Loisir et Société / Society and Leisure 21(2): 573-582. DOI: https:// doi.org/10.1080/07053436.1998.10753672.

Porter, S.R., and M.E. Whitcomb. 2005. "Non-Response in Student Surveys: The Role of Demographics, Engagement and Personality." Research in Higher Education 46(2): 127-152. DOI: https://doi.org/10.1007/s11162-004-1597-2.

Savage, M., and R. Burrows. 2009. "Some Further Reflections on the Coming Crisis of Empirical Sociology.” Sociology 43(4): 762-772. DOI: https://doi.org/10.1177/003803 8509105420 . 
Sax, L.J., S.K. Gilmartin, and A.N. Bryant. 2003. "Assessing Response Rate and Nonreponse Bias in Web and Paper Surveys." Research in Higher Education 44(4): 409-432. DOI: https://doi.org/10.1023/A:1024232915870.

Singer, E., R.M. Groves, and A.D. Corning. 1999. "Differential Incentives: Beliefs About Practices, Perceptions of Equity, and Effects on Survey Participation." Public Opinion Quarterly 63(2): 251-260. DOI: https://doi.org/10.1086/297714.

Singer, E., J. van Hoewyk, and M.P. Maher. 2000. "Experiments with Incentives in Telephone Surveys.” Public Opinion Quarterly 64(2): 171-188. DOI: https://doi.org/ 10.1086/317761.

Singer, J.D., and J.B. Willett. 2003. Applied Longitudinal Data Analysis. Modeling Change and Event Occurrence. New York (NY): Oxford University Press.

Smith, C., and D. Nutbeam. 1990. "Assessing Non-Response Bias: A Case Study from the 1985 Welsh Heart Health Survey.” Health Education Research 5(3): 381-386. DOI: https://doi.org/10.1093/her/5.3.381.

Smith, W.G. 2008. "Does Gender Influence Online Survey Participation? A RecordLinkage Analysis of University Faculty Online Survey Response Behavior.” Available at: https://files.eric.ed.gov/fulltext/ED501717.pdf (accessed August 2020).

Szalai, A. 1966. "Trends in Comparative Time-Budget Research." American Behavioral Scientist 9(9): 3-8. DOI: https://doi.org/10.1177/000276426600900901.

Van Ingen, E., I. Stoop, and K. Breedveld. 2008. "Nonresponse in the Dutch Time Use Survey: Strategies for Response Enhancement and Bias Reduction." Field Methods 21(1): 69-90. DOI: https://doi.org/10.1177/1525822X08323099.

Van Kenhove, P., K. Wijnen, and K. de Wulf. 2000. "The Influence of Topic Involvement on Mail-Survey Response Behavior.” Psychology \& Marketing 19(3): 293-301. DOI: https://doi.org/10.1002/mar.1053.

Wallace, D. 1954. “A Case For- and Against- Mail Questionnaires." Public Opinion Quarterly 18(1): 40-52. DOI: https://doi.org/10.1086/266484.

Zuzanek, J. 1998. "Non-Response in Time-Use Surveys: Do the Two Ends Meet?" Loisir et Société / Society and Leisure 21(2): 547-549. DOI: https://doi.org/10.1080/07053436. 1998.10753668.

Received June 2019

Revised April 2020

Accepted August 2020 